\title{
Território contaminado - impureza e mistura em conexões artísticas entre África e Brasil
}

Roberto Conduru

Universidade do Estado do Rio de Janeiro

\begin{abstract}
Resumo
O texto aborda a articulação de dimensões ocidentais e não ocidentais da arte produzida no Brasil desde o século XVI até o presente, focando em alguns processos, instituições, artistas e obras marcados por conexões entre Brasil e África: a espacialidade dos quilombos a partir de sua cartografia; as joias de crioulas; a arquitetura construída por mecardores de escravos e exescravos na região do golfo do Benim; a arte produzida nas e para as comunidades religiosas afrobrasileiras, com destaque para a obra de Deoscóredes Maximiliano dos Santos, o Mestre Didi.
\end{abstract}

\section{Palavras-chave}

Mestre Valentim. Quilombo. Mestre Didi. Joias de crioulas. Arquitetura dos agudás.

\begin{abstract}
The text addresses the articulation of Western and non-Western dimensions of Brazilian art from the 16th century to the present, focusing on some processes, institutions, artists and works made of connections between Brazil and Africa: the spatiality of quilombos from its cartography; the creole jewelry; the architecture built by slave traders and former slaves in the Benin Gulf region; the art produced in and for the AfroBrazilian religious communities, especially the work of Deoscóredes Maximiliano dos Santos, known as Master Didi.
\end{abstract}

Key words

Master Valentim. Quilombo. Master Didi. Creoule jewelry. Aguda architecture

Na década de 1780, o porto do Rio de Janeiro foi renovado para melhor atender as rotas de comércio internacional e configurar uma nova imagem para a porta de acesso à capital da mais importante colônia de Portugal. Jacques Funck, brigadeiro sueco a serviço da coroa portuguesa, foi encarregado das obras, que incluíam a reconstrução do cais e da fonte de abastecimento d'água, assim como do Largo do Paço, onde também se 
localizava o Paço dos Vice-Reis, o convento e a igreja dos carmelitas, e algumas residências. Contudo, para o projeto do chafariz, elemento proeminente no conjunto urbanístico, o vice-Rei, Luís de Vasconcelos, recusou os desenhos do engenheiro militar e encomendou sua reformulação a Valentim da Fonseca e Silva, um artista nascido no Brasil, sem formação acadêmica, cujo trabalho era valorizado então na cidade. Conhecido como Mestre Valentim, ele vinha produzindo retábulos e esculturas para ordens religiosas e algumas obras para o vice-Rei - o Passeio Público, primeiro jardim público no Brasil, e outras fontes d'água -, reinterpretando o gosto artístico difundido a partir de Lisboa naquela época.

Além das idiossincrasias estéticas do vice-Rei, esse episódio mostra como transitavam pelo porto do Rio de Janeiro muito mais do que embarcações, produtos e pessoas. Para consecução do novo chafariz, convergiram reelaborações suecas e portuguesas de recentes revisões francesas de ideias, princípios e formas artísticas dos antigos gregos e romanos. David Underwood (1994: 278) defende que Mestre Valentim “abrandou a geometria do Neoclassicismo internacional (...) e animou suas formas tratando as superfícies e massas do chafariz de uma maneira característica do escultor e entalhador colonial". Entretanto, sendo Mestre Valentim um mestiço, filho de um português e de uma africana, pode-se perguntar que papel tiveram em seu trabalho (não necessariamente entendido como abrandamento e animação) tradições artísticas derivadas de outra região: África.

Essa questão, passível de ser aplicada a realizações de outros momentos e lugares, pode ser desdobrada, estendendo-se por boa parte 
da história da arte relacionada ao Brasil. Com a transposição forçada de africanos ao Brasil para serem escravizados, entre os séculos XVI e XIX, como sobreviveram ideias, práticas e formas artísticas difundidas em suas regiões de origem? Como foram reinventadas em um contexto sociocultural que subjugava valores africanos? Como elas e suas reinvenções foram apropriadas por outrem, nos dois lados do oceano Atlântico e além?

Nesse sentido, interessa a difusão no Brasil de princípios, modos de fazer e objetos artísticos de alguns grupos sociais na África, mas também, na dinâmica inversa, o rebatimento em África de experiências no Brasil, assim como processos artísticos que envolvem estas e outras regiões nas dinâmicas socioculturais constitutivas do comércio e da colonização europeus em regiões ao Sul, da escravidão, do tráfico negreiro, da diáspora africana. Processos que permitem perceber como conexões entre Brasil e África atravessam a história da arte desde o século XVI até o presente, quando a cultura afro-brasileira é reconhecida como uma vertente sociocultural e se processa reflexivamente.

Entretanto, responder a questões como essas não é algo freqüente na historiografia da arte, nem é uma tarefa fácil. No que tange à arte produzida no Brasil, a pequena quantidade e o pequeno interesse na preservação de registros referentes a africanos e afro-descendentes dificulta o estudo de permanências e mudanças de artes da África no novo contexto, inibindo sua percepção nítida. Embora elementos de culturas africanas sejam facilmente perceptíveis e razoavelmente reconhecidos na língua, na música, na dança e na culinária praticadas no país, parecem difusos nas artes plásticas, emergindo com mais clareza de quando em 
vez, podendo ser detectados com apenas aqui e ali.

Agindo contra esta falta de nitidez, este texto aborda dimensões ocidentais e não ocidentais da arte produzida no Brasil desde o século XVI até o presente, focando em alguns processos, instituições, artistas e obras marcados por conexões entre Brasil e África: a espacialidade dos quilombos a partir de sua cartografia; as joias de crioulas; a arquitetura construída por mecardores de escravos e ex-escravos na região do golfo do Benim; a arte produzida nas e para as comunidades religiosas afrobrasileiras, com destaque para a obra de Deoscóredes Maximiliano dos Santos, o Mestre Didi. ${ }^{1}$

\section{Marcos territoriais afro-brasileiros}

Impedidos de reproduzir livremente suas culturas no Brasil, os africanos e seus descendentes foram coagidos e incentivados a usar suas potências corporais e conhecimentos para constituir o aparato físico e os símbolos necessários às ações dos colonizadores, majoritariamente portugueses, mas também espanhóis, franceses e holandeses em determinados períodos e regiões. Participaram, assim, da construção de cidades, edifícios militares, civis e religiosos, monumentos e obras de arte. Obrigados a seguir princípios e formas impostos a partir das metrópoles, eles contribuíram para o transplante e renovação das culturas artísticas européias no Brasil.

Neste processo, a arte católica foi um campo fértil para

\footnotetext{
${ }^{1}$ Este texto é parte do trabalho que subsisdiou o curso "Survival and Invention", ministrado em 2014 no programa de pós-graduação da Meadows School of the Arts, da Southern Methodist University, em Dallas. 
representações, mais ou menos enviesadas, de africanos e de afrodescendentes por meio da manipulação de códigos artísticos dominantes. Embora fossem expressões subjetivas que se aproveitavam de brechas no sistema de controle do imaginário, às quais foram imiscuídos elementos de religiões africanas, essas imagens não deixaram de corroborar a justificativa religiosa da escravidão, a subjugação de corpos e mentes com vistas à salvação das almas.

Um caso singular de ambivalente autorrepresentação é a igreja de Santa Efigênia, em Ouro Preto, que teria sido construída por Chico Rei. Senhor na África, escravo no Brasil, ele teria conseguido reconquistar a liberdade e reconstituir sua corte na América, após liberar um filho e alguns súditos com recursos provenientes da extração de ouro. Se a igreja manifestava publicamente sua conversão ao catolicismo, a presença em alguns retábulos de búzios, chifres de carneiro e outros signos ambíguos permitia falar na permanência de práticas religiosas africanas.

Marcas africanas não se inscreveram tranquilamente no território brasileiro, nem são de fácil percepção quando sobrevivem. Alguns autores defendem que a senzala teve origem em construções africanas (Gomes, 1998; Gomes, 2006; Gomes, 2008). Entretanto, mesmo admitindo a manutenção de valores africanos na intimidade dos escravos em suas habitações, que afetava os modos como se apropriavam das habitações a eles designadas, permanece a dúvida quanto ao grau de autonomia que os servos tinham na conformação das edificações e na estruturação das fazendas, cujos elementos arquitetônicos eram componentes importantes nos processos de geração de riqueza a partir da lavoura de cana-de-açúcar, café e outros produtos. Para Gunter Weimer (2005), depois dos 
portugueses, os africanos foram os que mais contribuíram para a arquitetura popular no Brasil, com uma tipologia diversificada, correspondente à variedade de suas origens, mas que foi afetada pela simplificação dos processos construtivos, sendo de difícil percepção.

Tanto nos espaços de representação da elite, quanto naqueles sob o seu controle, era difícil imiscuir referências e valores africanos. Nos quilombos, lugares de resistência ao jugo da escravidão e à ordem social dominante, pode-se supor que havia maior liberdade na configuração de edifícios e espaços, permitindo e incentivando a ressurgência de princípios e formas da arquitetura, do urbanismo e da paisagem em África. Contudo, embora estivem à margem da estrutura colonizadora, nos quilombos foram articuladas múltiplas referências: africanas, indígenas e européias. Sua complexidade espacial derivava dos diferentes grupos marginalizados que os constituíam: sobretudo ex-escravos africanos e afro-descendentes, mas também nativos e até europeus (Dos Anjos, 2009).

Assim como a arquitetura popular, também os quilombos submergiram na quase total invisibilidade, devido ao seu extermínio ou às transformações que sofreram ao longo do tempo. Além de ser quantitativamente pequena, a cartografia de quilombos foi elaborada não por seus idealizadores e habitantes, mas por aqueles que os pretendiam arrasar, dificultando pensar seus princípios de estruturação espacial. Não eram projetos dos quilombos, nem levantamentos feitos com a autorização e a colaboração de seus habitantes. Ao contrário, eram instrumentos operativos que visavam ao conhecimento de onde se localizavam e como se estruturavam esses espaços de resistência de escravos fugidos e de pessoas à margem da lei, para que fossem atacados e destruídos, fazendo 
seus habitantes retornar ao cativeiro e à ordem colonial dominante.

Embora os pontos vitais à sobrevivência e os elementos defensivos fossem fundamentais na vida cotidiana do quilombo, não é por acaso que sobressaem nas representações feitas pelos inimigos, em detrimento do detalhamento de suas especificidades territoriais e arquitetônicas, como acontece no mapa do Quilombo de São Gonçalo, existente em Minas Gerais. Neste desenho, o contraste entre o rigor geométrico na configuração dos limites da ocupação territorial e a imprecisão na caracterização das construções e de sua distribuição deriva de informações limitadas e projeções abstratizantes, pondo em dúvida o grau de veracidade desse artefato bélico. Entretanto, apesar do esquematismo e do silêncio expresso nos vazios gráficos, os sentidos produzidos pelas conexões entre palavras e imagens neste mapa permitem perceber a sobrevivência de tradições africanas de cultivo agrícola, produção de alimentos, forja de metais, fabrico têxtil. Além de valores paisagísticos, as sucintas indicações arquitetônicas e urbanísticas indicam diferenciação funcional e hierárquica entre as casas e seus usuários, sugerindo uma estruturação coletiva derivada da dominante questão defensiva e de padrões sociais africanos.

\section{Arte sacra emergente}

Entre os signos relacionados à África presentes no território brasileiro, sobressaem as comunidades das religiões afro-brasileiras batuque, candomblé, macumba, tambor de mina, terecô, umbanda e xangô, entre outras designações que indicam suas inflexões regionais - 
que são os mais longevos espaços de resistência afro à dominação cultural no Brasil. Mesmo após a transformação do Brasil em uma nação republicana e laica, em 1889, estas religiões continuaram sendo perseguidas, o que restringe suas práticas e a difusão de seu imaginário. Assim, vêm conquistando de modo paulatino a liberdade de culto e expressão pública de seus valores éticos e estéticos.

Neste processo, houve descontinuidade e mudanças em seus panteões, rituais e, conseqüentemente, nas conformações materiais de sua simbólica. Os ambientes religiosos foram reconfigurados a partir das exigências litúrgicas e de acordo com as possibilidades locais de produção e uso. A articulação de valores, ideias, formas e modos de fazer de determinadas sociedades africanas a outras referências de arte, arquitetura e design, gerou culturas materiais que permitiram a africanos e afrodescendentes constituir (auto)representações que foram por muito tempo mantidas em segredo ou dissimuladas publicamente.

Usualmente, os terreiros, como são designados os edifícios e espaços onde concentravam suas atividades religiosas, se localizavam nas áreas habitadas pela população mais pobre, fosse em áreas subvalorizadas das cidades ou na zona rural, e enfrentavam constantes pressões, que afetavam sobretudo a necessidade de contato com elementos da natureza. Menos ou mais constrangidas, essas comunidades muitas vezes precisaram ser transferidas, devido à especulação imobiliária, e quase sempre se adaptar a edifícios idealizados para outros fins. Esta estratégia de sobrevivência acabou gerando uma plasticidade dinâmica, inventiva e regeneradora potencializada pelo axé (simplificadamente, força espiritual), fixada menos em formas e estilos do que nas relações entre 
espaços, construções, coisas, seres, ações.

Maiores ou menores, os terreiros são metáforas vivas de civilizações africanas. Suas instalações - um conjunto de casas e cômodos, espaços cobertos e livres, criados para abrigar coisas e seres (pessoas, animais e plantas) do mundo terreno ou não - rementem a paisagens míticas de algumas regiões africanas. Dimensões espirituais da existência e sociabilidade pública são cultivadas nestas reinvenções da África, que transbordam um tanto discretamente no cotidiano brasileiro. (Sodré, 2002; Conduru, 2013)

Se os rituais demandam variados ambientes, materiais, artefatos, sons, gestos e ações, muitos lugares e coisas são engendrados ritualisticamente. Impensáveis sem cânticos, danças, objetos e espaços, essas práticas religiosas relativizam as distinções entre artes maiores e menores, entre artes cênicas, artes plásticas e música.

Não foi necessariamente positiva a maior visibilidade que os objetos usados nos rituais tiveram após 1889, como atestam as apreensões feitas em invasões policiais a terreiros, no início do século XX, e sua posterior exibição como provas criminais, de acordo com o código penal então vigente. Se a partir do final dos anos 1930 a legislação não mais permitiu a perseguição dessas religiões, até hoje seus fiéis enfrentam dificuldades para manifestar publicamente suas crenças.

No lento processo de mudança do entendimento social dessas religiões, uma etapa decisiva para a visão de parte de seus artefatos como obras de arte se deu em 1964, quando, incentivado por Juana Elbein dos Santos, sua esposa, Deoscóredes Maximiliano dos Santos começou a exibir em galerias de arte os cetros que produzia para rituais dos orixás Obaluaê 
e de Nanã - xaxarás e ibiris, respectivamente -, que aprendeu a produzir desde quando fora iniciado no candomblé, em 1925. Com o tempo, Mestre Didi, como é conhecido, também passou a elaborar objetos não ritualísticos com as mesmas técnicas e materiais: taliscas de dendezeiro (Elaeis guineensis), tiras de couro, palha, búzios, contas de vidro. Derivando de conhecimentos forjados na vivência cotidiana dos terreiros e no intercâmbio cultural mantido entre comunidades na Bahia e na região do golfo do Benim, suas esculturas e instalações são interpretações subjetivas de mitos religiosos, mas ultrapassam o campo da arte sacra.

Transposição de barreiras que ele iniciara em 1946, quando começou a publicar seus escritos no Brasil e no exterior: um dicionário Iorubá-Português, contos e outros textos sobre religião, arte e cultura africana e afro-brasileira. Além de começar a expor, nos anos 1960, ele viajou para realizar pesquisas comparadas entre Brasil e África, quando associou-se a centros de pesquisa e fez curadorias de exposições. Desde aquela época, especialmente após sua participação na mostra Magiciens de la Terre, em 1989, seu trabalho tem trânsito nacional e internacional, participando de exposições individuais e coletivas relacionadas à cultura afro-brasileira e da afro-diáspora.

A vida de Mestre Didi indica um contínuo e profundo aprimoramento de valores religiosos e artísticos nutridos entre os dois lados do Atlântico. E exemplifica como, nos terreiros das religiões afrobrasileiras, sobreviveram tecnologia e arte da África apesar dos lapsos processados no tempo e no espaço. Suas peças atestam a possibilidade de preservação dos atributos exigidos no culto e de sua extensão a outros domínios, em função de terem sentidos religiosos e artísticos, dentro e fora 
dos terreiros. Sua trajetória indica possibilidades de trânsito entre esses universos, de maior intervenção e pertencimento cultural para os afrodescendentes. Sua apresentação como “sacerdote-artista” (Santos, 2000) expressa verdadeiramente sua biografia, mas também dificulta que seja visto como artista tout court. Algo corroborado pela usual exposição de suas obras como contrapontos à arte do mainstream. Assim, Mestre Didi continua sendo uma exceção entre os artistas provenientes dos terreiros, cujos trabalhos geralmente são excluídos do circuito artístico erudito e de vanguarda no Brasil. Persiste, portanto, o interdito ao entendimento dos artefatos dessas religiões como obras de arte, corroborando a marginalização delas e de seus autores.

\section{Pérolas de emancipação}

Muitas lideranças femininas das comunidades religiosas afrobrasileiras, também chamadas de ialorixás e mães de santo, dividiam seu tempo entre os terreiros e as ruas, onde complementavam a renda vendendo quitutes salgados e doces, frutas, ervas e outros itens. Neste comércio, tiveram como precedentes as negras de ganho, mulheres negras escravizadas que eram autorizadas por seus senhores a obter recursos próprios, com os quais muitas vezes conquistaram a liberdade. Em suas aventuras pela cidade, essas mulheres portavam uma indumentária composta por saia rodada, bata, pano de cabeça, pano da costa, fios de contas e, por vezes, joias - indumentária que articulava precedentes africanos e europeus. Relatos, pinturas e fotografias atestam que enfeites preciosos também eram usados por algumas escravas domésticas, a 
mando de seus proprietários, visando à ostentação de riqueza (Lody, 2003; Godoy, 2006; Cunha, Milz, 2011).

Joias de crioula é como ficaram conhecidos os ricos adornos usados por essas negras cativas ou libertas: colares de bolas, colares de alianças ou grilhões, com cruzes, rosetas e outros pingentes, brincos, pulseiras em placas com cilindros, pulseiras em formato de copo, anéis, pentes, pencas de balangandãs. Peças feitas em ouro ou prata, às quais, em certos elementos, foram agregados outros materiais preciosos, ou nem tanto: coral, marfim, madeira.

No período em que o Brasil era uma colônia portuguesa, essa joalheria burlava a proibição feita pela metrópole quanto ao uso de trajes suntuários por alguns segmentos sociais. No âmbito da escravidão, em algumas situações os próprios senhores cuidavam de bem vestir e adornar as escravas com as quais conviviam no espaço doméstico e que, não raro, eram assim expostas publicamente, indicando a riqueza de seus proprietários. Além de se distinguirem socialmente por possuírem e exibirem essas joias, as mulheres negras libertas as tinham como um patrimônio com o qual podiam tanto garantir a sobrevivência em uma sociedade adversa para as ex-escravas, quanto comprar a liberdade de outros escravos, fossem seus parentes ou amigos.

Mas essa joalheria possuía outros atributos, uma vez que muitos dos elementos e materiais que as constituem têm significados mágicos e religiosos, sejam cruzes católicas, ou talismãs e amuletos referentes a crenças diversas, inclusive com sentidos africanos. Para garantir esta multiplicidade simbólica eram fundamentais os materiais, elementos, formas e modos de fabricação destas joias. A relação entre quantidade e 
qualidade era fundamental para compreender a singularidade delas. Não se constituindo de metal puro, nem sendo maciças, importava o volume das peças. O material devia ser explorado de modo a render visualmente, fazendo as joias e seus proprietários parecerem ser mais ricos do que efetivamente eram. Também com este fim, técnicas como a filigrana e o cinzelado eram manipuladas pelos ourives (anônimos e possivelmente africanos ou afro-descendentes) para expandir ao máximo o brilho do metal, gerando imagens de radiante opulência.

Estas joias também se distinguem por resultarem de intercâmbios estabelecidos a partir do antigo sistema colonial português, nos fluxos de pessoas, objetos, crenças e modas entre a metrópole, suas colônias e possessões. Sobretudo na Bahia, durante os séculos XVIII e XIX, a partir de onde e quando se difundiu este gosto, a tradição de ourivesaria do Noroeste de Portugal foi mesclada com referências dos akan, na África, e gerou uma joalheria única. Mais do que expressar riqueza, poder e beleza, esta joalheria tornou-se um signo de resistência, liberdade, intercâmbio, invenção.

Da maior ou menor clausura da escravidão, as joias de crioulas ganharam o mundo. As mulheres afro-descendentes que mercavam pelas ruas, algumas das quais possuiam e por vezes portavam publicamente esta joalheria, tornaram-se conhecidas como baianas, provavelmente por conta das mulheres negras que, após o fim da escravidão, migraram da Bahia para o Rio de Janeiro, então Capital Federal, à procura de melhores condições de vida, e constituíram na cidade comunidades familiares, religiosas e amplas redes de relacionamento. Sendo elos entre religião, carnaval, festa e vida popular, elas eram um complexo signo de alteridade,

$$
\begin{array}{r}
\text { Revista do Programa de Pós-graduação em Arte da UnB } \\
\text { V. 16, } \mathbf{n}^{0} 1 / \text { janeiro-junho de } 2017 \\
\text { Brasília } \\
\text { ISSN- 1518-5494 } \\
\text { ISSN (versão eletrônica): 2447-2484 }
\end{array}
$$


configurando um contra-poder na conjuntura do Rio de Janeiro pósabolicionista. Exercendo influência a partir das margens da sociedade, eram mal vistas pela elite, cujo sonho era configurar a Capital Federal da recém criada República como uma Paris tropical. (Gomes, 2003; Velloso, 1990)

No lento processo de valorização de elementos africanos e afrobrasileiros na cultura brasileira, que ganhou impulso com ações de artistas e intelectuais desde o final do século XIX e mereceu especial atenção durante o regime ditatorial do Estado Novo (1937-45), a baiana ganhou outra ressonância social: foi conduzida ao centro do imaginário nacional, eleita como um dos emblemas da brasilidade e exaltada em diversos contextos sociais, embora não desvinculada da exploração sexual e do racismo. Além do carnaval, em que era um elemento fundamental das escolas de samba e uma fantasia usada por mulheres e homens, adultos e crianças, a baiana ganhou representações em música, artes plásticas, teatro, cinema, literatura, museologia, concursos de beleza.

Um instante decisivo para sua entronização no panteão dos tipos sociais brasileiros se deu em 1939, quando Carmen Miranda recriou a indumentária de baiana para interpretar a canção O que é que a baiana tem?, de Dorival Caymmi, evocando um misto de religiosidade, ostentação e erotismo. Com ela e seus trajes de baiana, as joias de crioula chegaram até Hollywood e além; de elementos da cultura afro-brasileira, em boa parte religiosos, se tornaram atributos de um ícone laico e internacional. 


\section{Brasil tectônico na África}

Embora o contingente populacional que migrou forçosamente da África ao Brasil devido ao tráfico negreiro seja muito maior do que o número de pessoas que, também a partir do século XVI, seguiram o caminho inverso devido à dinâmica da exploração portuguesa, é importante ressaltar que os intercâmbios se deram nos dois lados do Atlântico. Por mais de três séculos, o deslocamento de pessoas, coisas e saberes gerou trocas constantes entre essas regiões.

Entre os desdobramentos em contextos africanos de realizações artísticas na América, destaca-se a arquitetura construída na região do golfo do Benim (atuais Togo, Benim e Nigéria) a partir do início do século XIX, por um grupo heterogêneo que é nomeado naquela região como agudá. Inicialmente, integraram esse grupo: mercadores de escravos de origem brasileira que comercializavam cativos a partir daquela região africana, e ex-escravos que retornaram do Brasil para lá, após serem capturados e expulsos por terem participado da rebelião de africanos de religião islâmica, ocorrida na Bahia em 1835, ou depois de conquistarem a liberdade ao longo do século XIX, sobretudo quando acabou a escravidão no país, em 1888. Relacionados entre si, mercadores de escravos, exescravos, seus descendentes e agregados produziram uma arquitetura que era nomeada como brasileira por remeter a experiências e realizações no outro lado do Atlântico, pois tinham como principais referências os solares rurais e os palacetes urbanos produzidos na economia do açúcar, entre os séculos XVI e XIX (Verger, 1968; Cunha, 1985; Guran, 2000; Guran, Conduru, 2016). 
Essa arquitetura senhorial no Brasil adaptou referências europeias e de outras regiões ocupadas pelos colonizadores europeus às condições locais (clima, materiais e modos de construção, mão-de-obra), variando ao longo do tempo (dos séculos XVI ao XIX) e do espaço (Nordeste e Sudeste, especialmente na Bahia, em Pernambuco e no Rio de Janeiro). Também a arquitetura dos agudás adaptou referências diversas às condições de possibilidade e se transformou técnica e formalmente, entre o início do século XIX e meados do século XX, ao longo da costa do golfo do Benim, para continuar distinguindo socialmente seus construtores e usuários.

Os intercâmbios comerciais e culturais estabelecidos a partir do Atlântico foram fundamentais para a imagem e o processo produtivo dessa arquitetura. Sua construção contou com pedreiros e carpinteiros treinados no Brasil durante a experiência no cativeiro, mas também com africanos enviados à Bahia como aprendizes.

Em relação à técnica, inicialmente o adobe foi tornado mais resistente com o uso de elementos marítimos e associado a barrotes de madeira, permitindo a construção de sobrados, que eram excepcionais naquele contexto então. Uma primeira transformação se deu com a introdução do fabrico de tijolos e telhas cerâmicas na região, que foi sucedido pelo emprego do concreto armado.

Também a linguagem arquitetônica sofreu alterações. Aos poucos, as referências da arquitetura dos antigos gregos e romanos, presentes em elementos arquitetônicos e decorativos, deixaram de provir preferencialmente do contexto brasileiro. Mais do que substituir o rebatimento das artes geradas na colonização portuguesa pela cultura da belle époque, foram ondas de modernidade que se superpuseram quando os 
agudás passaram a acompanhar, um tanto indiretamente, os fluxos de difusão da arquitetura acadêmica europeia.

Elementos arquitetônicos e decorativos, alguns de luxo, foram importados do Brasil e de regiões produtoras: janelas com vidro, balcões de ferro, azulejos, peças em faiança. Pinturas ornamentais, móveis, fotografias e jardins foram outros elementos que causaram surpresa quando apareceram nas casas dos agudás.

Embora essa arquitetura seja caracterizada majoritariamente por residências, apresenta alguns exemplos de mesquitas, templos para culto de orixás e voduns, tumbas funerárias, e até mesmo um jardim público com um coreto, em Lomé, no Togo. Além de técnicas construtivas, formas arquitetônicas e ornamentais, os agudás introduziram naquela região novos elementos e práticas sanitaristas: dispositivos arquitetônicos para maior aeração e iluminação dos ambientes, sistemas de esgoto de detritos e de sepultamento de corpos.

Edifícios, móveis, fotografias, jardins, templos, tumbas funerárias e outros espaços estavam associados a vestimentas, comidas, crenças e hábitos também inovadores naquele contexto, constituindo um diferente modo de vida. Embora fosse um modo peculiar de reconstrução identitária, na qual ex-escravos incorporavam valores, signos e hábitos de seus antigos senhores, essa maneira de viver conectava os agudás à vida cultural no outro lado do Atlântico e os caracterizava como agentes de modernização, os diferenciando na região. Por também ser especialmente atraente para pessoas ávidas por uma cultura material de cunho ocidental, contemporânea, porém adaptável às tradições locais, essa arquitetura logo se tornou um meio de investimento e de especulação para seus 
realizadores. Com o tempo, passou a ser vista como parte de uma tradição que ainda hoje é cultivada.

Estes modos de construir, empreender e viver determinaram bairros particularmente identificados com o Brasil em cidades costeiras do golfo do Benim: Lomé e Aneho, no Togo, Widah e Porto Novo no Benim, Lagos, na Nigéria. Com sua presença no território, essa arquitetura funcionava como um signo tanto de modernidade em sentido amplo formal, técnica e sociocultural - quanto de reinvenção do Brasil em África.

\section{Contaminações}

De maneira bem livre, em fluxos não lineares e descontínuos, a arquitetura dos agudás estendeu a arte iniciada pelos antigos gregos e romanos ao golfo do Benim oitocentista. Os mapas, edifícios, cetros e joias antes vistos também resultam de misturas em processo que envolveram agentes, ideias, formas e técnicas de diferentes contextos no Brasil, na Europa, na África e além. Outros momentos poderiam ser focados: as trajetórias e obras dos ditos pintores negros, atuantes entre as últimas décadas do século XIX e as primeiras do século seguinte - Estevão Silva, Antônio Firmino Monteiro, Antônio Rafael Pinto Bandeira, e os irmãos João e Arthur Thimótheo da Costa; o culto do primitivismo desde o movimento modernista, nas obras de Agnaldo Manoel dos Santos, Arthur Bispo do Rosário, Chico Tabibuia e Heitor dos Prazeres, entre outros; a fusão de princípios e formas do construtivismo e das religiões afrobrasileiras na obra de Rubem Valentim; a associação de princípios e procedimentos típicos da arte na contemporaneidade a ritos, materiais, 
artefatos e imagens constitutivos das religiões afro-brasileirasas, nas obras de Ayrson Heráclito, Frente 3 de Fevereiro, Jorge dos Anjos e Rosana Paulino, entre outros; a articulação de Brasil, África e arte como problemas socioculturais para além de limites étnico-raciais em ações e obras de Abdias do Nascimento, Rubem Valentim, Marianno Carneiro da Cunha (1983) e Emanoel Araújo. ${ }^{2}$

Um conjunto heterogêneo. Seja porque interações socioculturais eram próprias às sociedades africanas das quais as pessoas foram levadas forçadamente para serem escravizadas nas Américas. Seja porque acumular, articular, miscigenar foram práticas adotadas como estratégias de sobrevivência no regime escravocrata. Ou ainda porque a ação exploratória e colonizadora dos portugueses se processou em uma faixa no globo terrestre que perpassa América, África e Ásia, amalgamando princípios, formas e modos de fazer dos dominadores aos das culturas artísticas subjugadas naqueles continentes, configurando o que Gilberto Freyre nomeou como "civilização luso-tropical" (Freyre, 2003). Mistura de misturas que, explicitando a impureza da arte no Brasil, tornam difícil situá-la no campo ocidental ou não-ocidental. E ajudam a ver quão contaminados são tanto estes campos quanto o descontínuo e fragmentário território constituído pelas conexões artísticas entre África e Brasil.

\footnotetext{
2 Artistas, objetos e questões abordados na outra parte do trabalho, incluída em uma coletânea de ensaios sobre Artes Visuais, organizada por Fernando Cochiaralle e editada pela Funarte, que está atualmente no prelo. 


\section{Referências}

CONDURU, Roberto. Das casas às roças - comunidades de candomblé no Rio de Janeiro desde o fim do século XIX. In: CONDURU, Roberto. Pérolas negras - primeiros fios: experi6encias artísticas e culturais nos fluxos entre África e Brasil. Rio de Janeiro: EdUERJ, 2013, p. 159-192.

CUNHA, Laura; MILZ, Thomaz. Joias de Crioula. São Paulo: Editora Terceiro Nome, 2011.

CUNHA, Marianno Carneiro da. Arte afro-brasileira. In: ZANINI, Walter (organizador). História geral da arte no Brasil. São Paulo: Instituto Walter Moreira Salles, 1983.

CUNHA, Marianno Carneiro da. Da senzala ao sobrado: arquitetura brasileira na Nigéria e na República Popular do Benim. São Paulo: Nobel; Edusp, 1985.

DOS ANJOS, Rafael Sanzio Araújo. Quilombos: geografia africana, cartografia étnica, territórios tradicionais. Brasília: Mapas Editora \& Consultoria, 2009.

FREYRE, Gilberto. Arte e civilização moderna nos trópicos: a contribuição portuguesa e a responsabilidade brasileira. In: FREYRE, Gilberto. China tropical. Brasília: Editora da UnB; São Paulo Imprensa Oficial do Estado, 2003.

GODOY, Solange de Sampaio. Círculo de contas: jóias de crioulas baianas. Salvador: Fundação Museu Carlos Costa Pinto, 2006.

GOMES, Geraldo. Engenho E arquitetura. Recife: Fundação Gilberto Freyre, 1998.

GOMES, Geraldo. Engenho e Arquitetura. Recife: Fundaj; Massangana, 2006.

Arquitetura do açúcar. In: BICCA, Briane Elizabeth Panitz; BICCA, Paulo Renato Silveira (organizadores). Arquitetura na Formação do Brasil. Brasília: Unesco, Iphan, 2008, p. 82-123. 
GOMES, Tiago de Melo. Para além da casa de Tia Ciata: outras experiências no universo cultural carioca, 1830-1930. Afro-Ásia. Salvador: UFBA, v. 29-30, p. 175-188, 2003.

GURAN, Milton. Agudás: os “brasileiros" do Benim. Rio de Janeiro: Nova Fronteira, 2000.

GURAN, Milton; CONDURU, Roberto. Architecture Agudás au Bénin et au Togo. Brasília: Nova Ministério das relações Exteriores, 2016.

LODY, Raul. O que que a bahiana tem: pano-da-costa e roupa de baiana. Rio de Janeiro: FUNARTE, CNFCP, 2003.

MOURA, Roberto. Tia Ciata e a Pequena África no Rio de Janeiro. Rio de Janeiro: Secretaria Municipal de Cultura, Departamento Geral de Documentação e Informação Cultural, Divisão de Editoração, 1995.

SANTOS, Juana Elbein dos. Tradição e contemporaneidade: poesia mítica. In: Mestre Didi. São Paulo: Galeria São Paulo: 2000.

SODRÉ, Muniz. O terreiro e a cidade: a forma social negro-brasileira. Salvador: Secretaria da Cultura e Turismo; Imago, 2002.

TRINDADE, Simone. Les chaînes garnies de pendentifs (pencas de balangandãs) et la force magique des fruits et des animaux. In: STOLS, Eddy (organizador). Terra Brasilis. Anvers: Ludion, 2011, p. 126-129.

UNDERWOOD, David K. The chafariz do Largo Paço in Rio de Janeiro. In: DEL BRENNA, Giovanna Rosso (organizadora). La construzione di un Nuovo Mondo: territorio, cittá, archittetura tra Europa e America Latina dal XVI ao XVIII secolo. Genova: Sagepe, 1994, p. 278-281.

VELLOSO, Mônica Pimenta. As tias baianas tomam conta do pedaço. Espaço e identidade cultural no Rio de Janeiro. Estudos Históricos. Rio de Janeiro: v. 3, n. 6, p. 207-228, 1990.

VERGER, Pierre. Fluxo e refluxo do tráfico de escravos entre o Golfo do Benin e a Baía de Todos os Santos, dos séculos XVII a XIX (1968). Salvador: Corrupio, 1987.

WEIMER, Günter. Arquitetura popular brasileira. São Paulo: Martins Fontes, 2005. 